\title{
Compressive Strength and Microstructure Analysis of Treated Rice Husk Ash (TRHA) Incorporated Mortar
}

\author{
Siti Asmahani Saad ${ }^{1 *}$, Nasir Shafiq², Mariana Mohamed Osman ${ }^{3}$, Siti Aliyyah Masjuki ${ }^{4}$ \\ ${ }^{1}$ Kulliyyah of Engineering, International Islamic University Malaysia, Malaysia \\ ${ }^{2}$ Faculty of Engineering, University of Technology PETRONAS, Malaysia \\ ${ }^{3}$ Kulliyyah of Architecture and Environmental Design, International Islamic University Malaysia, Malaysia \\ *Corresponding author E-mail: asmahanisaad@iium.edu.my
}

\begin{abstract}
High amount of reactive silica is ubiquitous in pozzolanic reaction for concrete strength increment. Rice husk ash (RHA) is proven contains high content of amorphous silica that is essential in the pozzolanic reaction of effective additive in concrete. Nevertheless, incorporation of RHA as cement replacement material (CRM) or additive is very minimal in current concrete industry. Therefore, improvement on the RHA properties by introduction of thermal and chemical pretreatment prior to incineration process is considered as a promising way in order to achieve the goal. This treatment process has been reported widely in literature. In this paper, the effect of treated rice husk ash (TRHA) and non-treated rice husk ash (NTRHA) incorporated mortar in terms of its compressive strength and microstructure properties are examine subsequently. The strength activity of TRHA from the optimum treatment process was measured by testing the compressive strength of mortars. The highest compression value obtained was $50.73 \mathrm{MPa}$ with $3 \%$ UFTRHA replacement at 28 days. At a longer curing period i.e. 90 days, it was recorded that $3 \%$ of UFTRHA mortar had the highest compression value at $53.87 \mathrm{MPa}$. As for microstructure properties, a denser microstructure with excellent aggregate bonding and cement matrix in the interfacial transition zone (ITZ) was observed.
\end{abstract}

Keywords: Compressive strength; microstructure properties; physicochemical properties of rice husk ash (RHA); cement replacement material (CRM); Treated Rice Husk Ash (TRHA); Non-Treated Rice Husk Ash (NTRHA); high energy milling.

\section{Introduction}

Construction industry that adopts high quality material encourages engineers to find new innovations in building technology. The major constituent of concrete is aggregate, which may be natural e.g. gravel or crushed rock with sand or artificial such as blast furnace slag, broken brick and steel shot. Another constituent is the binder that is quite expensive to produce but important as it serves to hold together the particles of aggregate to form concrete [1]. In advance construction technology development, utilization of additive materials are essential in order to produce a better performance of concrete. In this regard, mineral additive materials which possess pozzolanic behavior are favorable to be added into cement mixture due to its properties that promotes the concrete strength development. In current production of high performance concrete (HPC) and ultra-high performance concrete (UHPC), most of the researchers incorporates silica fume (SF) and pulverized fuel ash (PFA). High demand of these materials in construction industries cause supply shortage, and hence price hike. Since rice husk is an agricultural waste, usage of RHA in concrete therefore is favorable in terms of material cost reduction. Thus, incorporation of RHA in concrete production promotes environmental as well as economic relief. Comparing to other additive materials type such as silica fume (SF) and fly ash (FA), RHA is proven to have greater reaction with portlandite $\left(\mathrm{Ca}(\mathrm{OH})_{2}\right)$ in pozzolanic reaction, contributing towards increment in compressive strength value and durability of HPC [2], [3] and UHPC as well [4].
Green technology approach is a prominent way in promoting sustainability. Recently, an extensive research on incorporation of RHA in concrete has been done due to high in silica content. Production of RHA is completed thru a thermal activation by burning the raw rice husk to ash. Despite of high number of experimental works done in this area since 1970s, quality of the RHA produced is still compromised. Unlike other type of material such as fly ash and silica fume, this material is still not widely used as additive material among the construction key players, although the research of the RHA has begun in 1970s.

Since rice is regarded as a staple food of many Asian countries including Malaysia, rice production reaches nearly 1000 Million tons each year. As a result of this massive agriculture production, generated rice husks from rice milling process are about 400 Million tons [5]. Therefore, the potential of producing ash from husk is approximately 100 million tons annually. In light of this matter, utilizing RHA in concrete is sustainable. In addition, significant amount of amorphous silica as well as large specific surface area (SSA) of RHA are able to be attained by introducing suitable burning state [6]. Comparing to other additive material type such as silica fume (SF) and pulverized fuel ash (PFA), RHA is proven to have greater reaction with portlandite $\left(\mathrm{Ca}(\mathrm{OH})_{2}\right)$ in pozzolanic reaction, contributes towards increment in compressive strength value and durability of high performance concrete [2], [3] and ultra-high performance concrete [4].

In order to obtain high amount of amorphous and reactive silica content that benefits pozzolanic reaction from rice husk, impurities are removed via thermochemical treatment process using acid such as hydrochloric $(\mathrm{HCl})$ acid and nitric $\left(\mathrm{HNO}_{3}\right)$ accordingly as re- 
ported by many researchers [3], [7], [8]. In this paper, the effect of treated rice husk ash (TRHA) incorporated mortar in terms of its compressive strength and microstructure properties are examine accordingly.

\section{Methodology}

\subsection{Production of Treated Rice Husk Ash (TRHA)}

The fresh rice husk was ascertained from local rice factory in Perak. The fresh rice husk was treated using $0.1 \mathrm{M}$ hydrochloric acid before burning procedure took place. During the treatment process, the sample were soaked and heated in the acid solution at $80^{\circ} \mathrm{C}$ [9]. After that, the sample was incinerated using laboratory furnace at $700^{\circ} \mathrm{C}$ for 1 hour. The treated rice husk ash (TRHA) was then milled by means of planetary ball milling process for 15 minutes to reduce the particle size as reported previously [6].

\subsection{Compression Test Analysis of Treated Rice Husk Ash (TRHA) Mortar}

In this investigation, compressive strength test for mortar cube was performed according to BS 4550 part 6: 1978 [10]. This standard contained procedures for preparing, casting, curing and testing of the mortar cube specimens. Mortar cube of $50 \mathrm{~mm}^{3}$ size was prepared to complete the experimental works. The cubes then were tested at age of 3, 7, 28, 56 and 90 days using 3 cubes at every concrete age. The test was conducted using compression machine model ELE ADR with $3000 \mathrm{kN}$ compression capacity. Details of mortar mixture proportioning is as outlined in Table 1.

Table 1: Detail of mortar mixture proportioning.

\begin{tabular}{|c|c|c|c|c|c|}
\hline Mixture & \multirow{2}{*}{$\begin{array}{l}\text { Cement Re- } \\
\text { placement } \\
\text { Percentage } \\
(\%)\end{array}$} & $\begin{array}{c}\text { Mype I } \\
\text { Cement }\end{array}$ & Water & $\begin{array}{c}\text { Fine Ag- } \\
\text { gregate }\end{array}$ & TRHA \\
\cline { 3 - 6 } & 0 & 500 & 250 & 1350 & 0 \\
\hline M500-0 & 1 & 495 & 250 & 1350 & 5 \\
\hline $\begin{array}{c}\text { M500-1- } \\
\text { T-700 }\end{array}$ & 2 & 490 & 250 & 1350 & 10 \\
\hline $\begin{array}{c}\text { M500-2- } \\
\text { T-700 }\end{array}$ & 3 & 485 & 250 & 1350 & 15 \\
\hline $\begin{array}{c}\text { M500-3- } \\
\text { T-700 }\end{array}$ & 4 & 480 & 250 & 1350 & 20 \\
\hline $\begin{array}{c}\text { M500-4- } \\
\text { T-700 }\end{array}$ & 5 & 475 & 250 & 1350 & 25 \\
\hline $\begin{array}{c}\text { M500-5- } \\
\text { T-700 }\end{array}$ & 1 & 495 & 250 & 1350 & 5 \\
\hline $\begin{array}{c}\text { M500-1- } \\
\text { NT-700 }\end{array}$ & 2 & 490 & 250 & 1350 & 10 \\
\hline $\begin{array}{c}\text { M500-2- } \\
\text { NT-700 }\end{array}$ & 3 & 485 & 250 & 1350 & 15 \\
\hline $\begin{array}{c}\text { M500-3- } \\
\text { NT-700 }\end{array}$ & 3 & 480 & 250 & 1350 & 20 \\
\hline $\begin{array}{c}\text { M500-4- } \\
\text { NT-700 }\end{array}$ & 4 & 475 & 250 & 1350 & 25 \\
\hline $\begin{array}{c}\text { M500-5- } \\
\text { NT-700 }\end{array}$ & 5 & & & & \\
\hline
\end{tabular}

\subsection{Microstructure Analysis of Treated Rice Husk Ash (TRHA) Mortar}

Scanning Electron Microscopy (SEM) analysis was carried out to determine the inner condition that is the microstructural properties of the concrete. This analysis is able to determine interfacial transitional zone (ITZ) structure of concrete samples as well. The analysis was performed using FESEM model Zeiss Supra 55 VP instrument. As for completion of this investigation, mortar samples cured at 90 days were cut using diamond cutter. The sample had to be conductive for full observation. Therefore, the specimens were coated accordingly prior to FESEM analysis completion. Concrete, as a non-conductive material, must be coated with gold atoms in sputter coater. Coated concrete was then placed in the vacuum chamber inside the FESEM testing equipment.

\section{Results and Discussion}

\subsection{Compressive Strength Analysis of Treated Rice Husk Ash (TRHA) Mortar}

The compression test result of hardened mortar during early and extended curing period of TRHA incorporated mortar is shown in Fig.1. Generally, rapid development of compressive strength values were recorded at as early as 3 days of curing period for all TRHA incorporated specimens i.e. $1 \%-5 \%$ replacement of TRHA. This were where the TRHA incorporated specimens performed higher early strength development than that of the control i.e. $17 \%-51 \%$ strength increment. As the curing period went up to 28 days, it was observed that TRHA replacement at $3 \%$ had the highest compression value of $50.73 \mathrm{MPa}$. The second highest compression value was followed by $4 \%$ of TRHA replacement at $49.07 \mathrm{MPa}$. Next were $2 \%, 1 \%$ and $5 \%$ of TRHA incorporations with the results of 44.47MPa, $41.07 \mathrm{MPa}$ and $46.60 \mathrm{MPa}$ respectively.

On the other hand, Fig. 2 illustrates the compressive strength data with $1-5 \%$ of cement replacement with non-treated RHA (NTRHA). At early age of mortar for NTRHA samples, the compressive strength development presented a slower strength development than control samples (with 5\% NTRHA incorporation) i.e. $8.12 \%$ lower compared to the control samples at 3 days mortar age for NTRHA-700 mortar specimens. These findings are similar to the previous finding that used non-treated RHA as cement replacement material in concrete. According to Kishore et al. (2011), cement replacement with non-treated RHA leads to decrease in the compressive strength [11]. Therefore, acid pretreatment of rice husk prior to burning process is essential in order to improve the produced RHA as effective pozzolans in concrete.

On the other hand, acceleration of compressive strength development at the early curing period is probably attributed by the degree of fineness and high specific surface area (SSA) of $\mathrm{SiO}_{2}$ content in TRHA that directly involved in the pozzolanic reaction. Hence, this phenomenon consolidated the formation of early denser hydrated cement matrix, which will improve the compression value of the TRHA mortar samples.

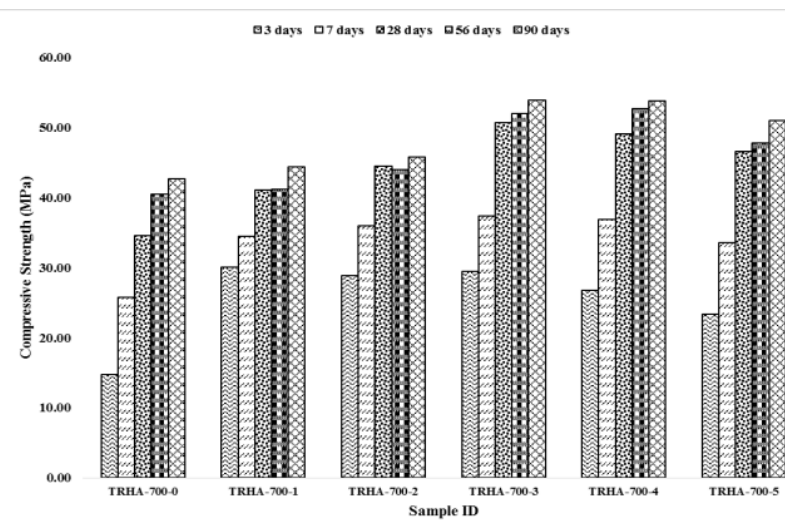

Fig. 1: Compressive strength development of mortar containing TRHA

\subsection{Microstructure Analysis of Treated Rice Husk Ash (TRHA) Mortar}

In order to understand further on microstructural properties of TRHA mortar, images after 90 days of curing period were captured and recorded accordingly using field emission scanning electron microscopy (FESEM) equipment. Fig. 3-5 display the FESEM images that showed interfacial transitional zone (ITZ) between aggregate and cement paste matrix for control sample, 3\% TRHA700 replacement and 3\% NTRHA replacement, respectively. 


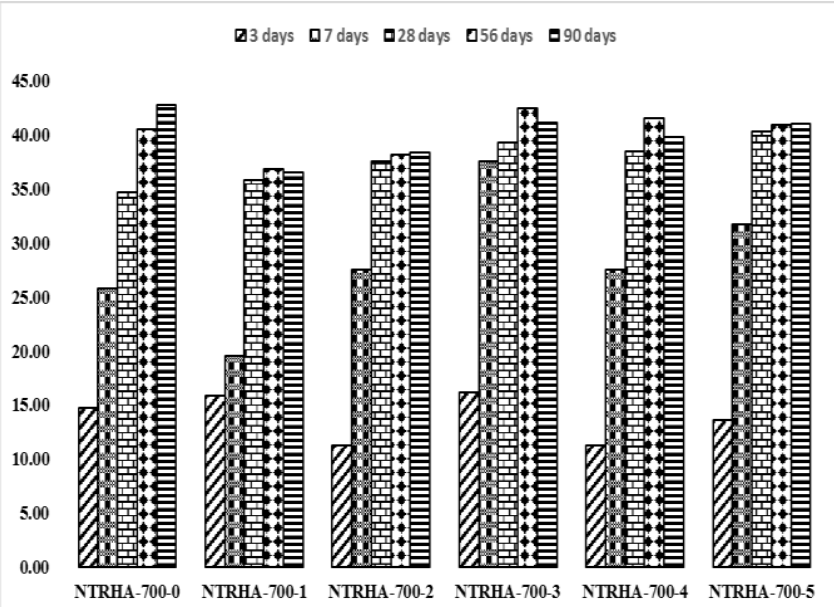

Fig. 2: Compressive strength development of mortar containing NTRHA.

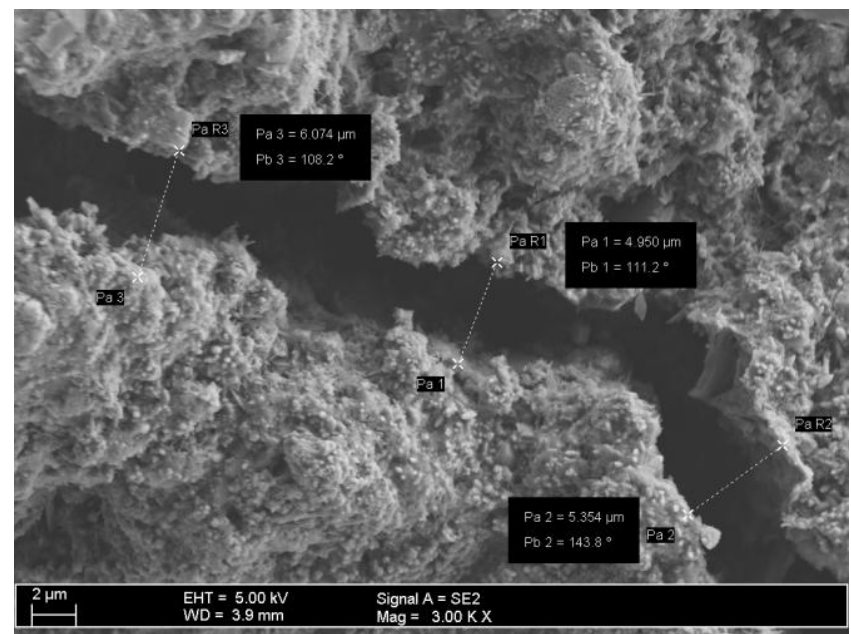

Fig. 3: FESEM image of interfacial transitional zone (ITZ) for control sample.

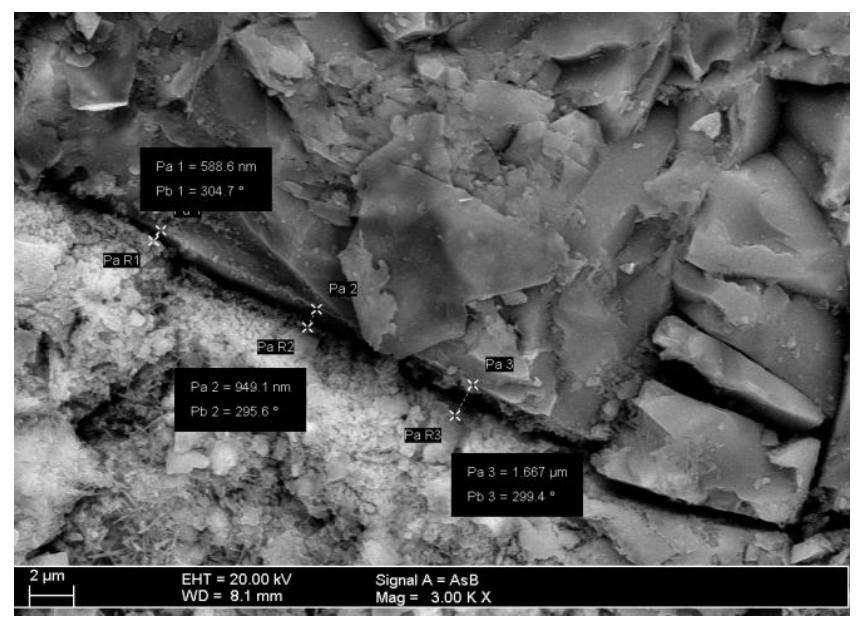

Fig. 4: FESEM image of interfacial transitional zone (ITZ) for mortar sample with 3\% TRHA-700 incorporation.

Based on the illustrated figures, a clear evidence is shown where the higher strength possessed by mortar sample with 3\% of TRHA incorporation compared to the control sample and NTRHA-700 sample. A denser microstructure with excellent aggregate bonding and cement matrix in the transition zone was observed. This condition resulted towards effective load transfer throughout the mortar framework and hence, higher compressive strength. From the FESEM investigation, it is proven that the mortar sample with $3 \%$ of TRHA incorporation reduces ITZ gap from micron-size i.e. to nano-size than that of the control as well as NTRHA-700 specimens, subsequently.

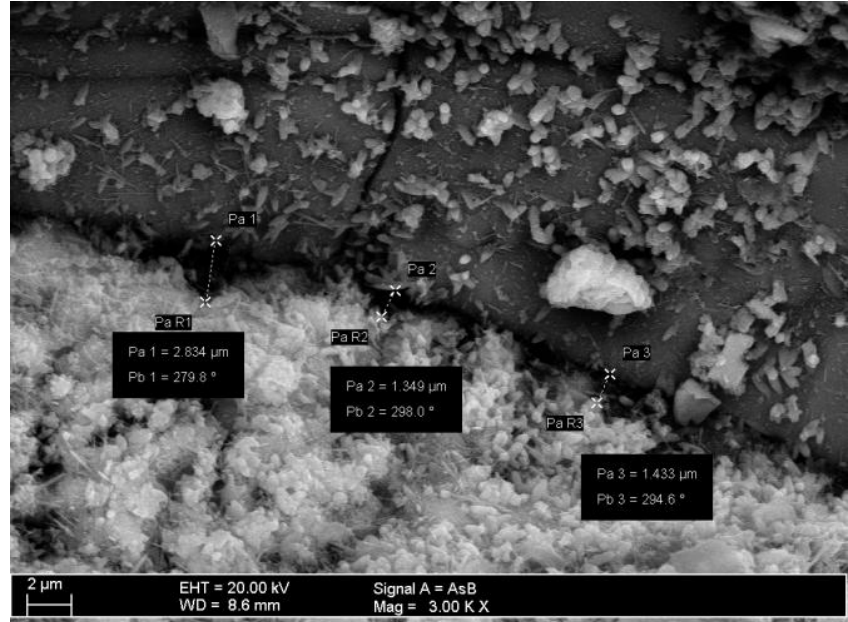

Fig. 3 (c): FESEM image of interfacial transitional zone (ITZ) for mortar sample with 3\% NTRHA-700 incorporation.

\section{Conclusion}

From the acquired results, the strength activity of TRHA from the optimum pretreatment process was measured by testing the compressive strength of mortars. The highest compression value obtained was $50.17 \mathrm{MPa}$ with $3 \%$ UFTRHA replacement at 28 days. It can also be concluded that small amount of UFTRHA is sufficient to attain certain compression value for instance, at only $1 \%$ UFTRHA replacement, compression value at 3 days of curing age increased about $50.9 \%$ for UFTRHA-700 compared to the control samples. Incorporation at 3\% were observed to exhibit highest compression value of 50.73MPa for UFTRHA-700 at 28 days. At the longest curing period e.g. 90 days, 3\% of UFTRHA-700 incorporation were recorded to have highest compressive strength with value of $57.87 \mathrm{MPa}$.

\section{Acknowledgement}

The author would like thank to the Ministry of Education of Malaysia $(\mathrm{MoE})$ for funding the research work under MyRa Grant Scheme. The author also wishes to express her profound gratitute to the staffs of Department of Civil Engineering of Universiti Teknologi PETRONAS and International Islamic University Malaysia for their endless support and help.

\section{References}

[1] Neville AM (2012), Properties of Concrete, $5^{\text {th }}$ Edition, Prentice Hall Pearson, pp. 745-750.

[2] Feng Q, Yamamichi H, Shoya M \& Sugita S (2004), Study on the pozzolanic properties of rice husk ash by hydrochloric acid pretreatment, Cem. Concr. Res., vol. 34, no. 3, pp. 521-526.

[3] Salas A, Delvastro S, Gutierrez RMD, \& Lange D (2009), Comparison of two processes for treating rice husk ash for use in high performance concrete, Cem. Concr. Res., vol. 39, no. 9, pp. 773-778.

[4] Van Tuan N, Ye G, Van Breugel K \& Copuroglu O (2011), Hydration and microstructure of ultra high performance concrete incorporating rice husk ash, Cem. Concr. Res., vol. 41, no. 11, pp. 1104-1111.

[5] Food and Agriculture Organization, Rice Market Monitor April 2015 (2015), available online: http://www.fao.org/fileadmin/templates/est/COMM_MARKETS_ MONITORING/Rice/Images/RMM/RMM_APR15.pdf, last visit: 10 July 2018

[6] Fadhil M, Saad SA, Shafiq N \& Ali M (2016), The effect of incineration temperature to the chemical and physical properties of ultrafine treated rice husk ash (UFTRHA) as supplementary cementing material (SCM), $4^{\text {th }}$ International Conference on Process 
Engineering and Advanced Material, Proceedia Engineering, vol 148, pp. 163-167.

[7] Park C, Salas A, Chung CW \& Lee CJ (2014), Freeze-thaw resistance of concrete using acid-leached rice husk ash, KSCE Journal of Civil Engineering, vol. 18, no.4, pp. 1133-1139.

[8] Vayghan AG, Khaloo AR \& Rajibipour F (2013), The effect of a hydrochloric acid pre-treatment on the physicochemical properties and pozzolanic performance of rice husk ash," Cem. Concr. Compos., vol. 39, pp. 131-140.

[9] Nuruddin MF, Saad SA, Shafiq N \& Ali M (2016), Effect of pretreatment soaking duration to characteristic of ultrafine treated rice husk ash (UFTRHA) as supplementary cementing material (SCM), ARPN J. Eng. Appl. Sci., vol. 11, no. 12, pp. 7596-7600.

[10] BSI (1978), BS 4550:Part 6 Method of Testing Cement. Standard Sand for Mortar Cubes, British Institute, London.

[11] Kishore R, Bhikshma V \& Jeevana Prakash P (2011), Study on strength characteristics of high strength Rice Husk Ash concrete, Procedia Eng., vol. 14, pp. 2666-2672. 